\title{
Gut
}

Leading article -Tropical infection of the gastrointestinal tract and liver series

\section{Parasitic infections of the small intestine}

The tropics support a diverse group of protozoal and helminthic pathogens that inhabit the small bowel of humans. Warm temperatures permit ova to survive for prolonged periods of time and support the maturation of ova and larvae into infectious forms. Poor sanitation and hygiene, low standards of education, and close contact between persons living at a subsistence level with the environment favour the spread of intestinal parasites. Human infection typically follows ingestion of contaminated food or water, or invasion of larva through exposed skin.

Parasites can be divided into two main groups, protozoa and helminths. Protozoa are single celled organisms, which can multiply in their hosts. Infection with even one protozoan can result in severe, life threatening disease. In general protozoal infections are not associated with eosinophilia. In contrast helminths are multicellular, multisystem organisms, often with complex life cycles. They are composed of the roundworms (nematodes) and the flatworms (platyhelminths), which include flukes (trematodes) and the tapeworms (cestodes). Most of them must develop in soil or in intermediate hosts before they become infectious for humans; few are capable of autoinfection.

The morphology, life cycle, metabolism, and susceptibility to chemotherapeutic agents are often similar for members of the helminthic genera. In some instances ova are ingested, excyst in the small intestine, and develop to adulthood, and adults reside there for the rest of their lives. In others helminths follow a complex path through the body before coming to reside in the small intestine as adults. Eosinophilia is common when larvae migrate through tissue, but it is often not seen when adult helminths are present only in the gastrointestinal tract.

The manifestations of helminthic infections depend on the pathogenicity of the parasite, the host immune response, and the worm burden. People with a limited number of adult helminths are often asymptomatic, although on occasion even a single worm can produce life threatening pathology as for example, when an adult Ascaris lumbricoides obstructs the pancreatic duct. Some human parasites, like the beef tapeworm Taenia saginata, are well adapted to their human host and produce minimal evidence of disease despite their large size. Other helminths cause significant tissue damage by direct toxic effects or by eliciting damaging immune responses. In general, the greater the parasite burden, the higher the likelihood of disease.

The signs and symptoms of protozoal and helminthic infections of the gastrointestinal tract are variable. Abdominal pain, diarrhoea, and weight loss may be seen.
The clinical presentation is complicated by the fact that people living in the tropics may be infected with multiple parasitic species as well as enteropathogenic bacteria and viruses. In general the diagnosis of intestinal parasite infection is made by identifying cysts, ova or larvae in the stool. In several instances sensitive and specific assays have been developed to detect parasite antigens in the stool. Effective chemotherapy is available for most but not all of the protozoal and helminthic pathogens that inhabit the bowel. Attempts to develop effective forms of immunoprophylaxis have not yet yielded successful vaccines.

The Table lists the parasites that produce pathology in the small intestine.

Protozoa that produce pathology in the small intestine The previous decade has been a period of dynamic change in the understanding of protozoal infections of the small

Parasitic infections affecting the small intestine

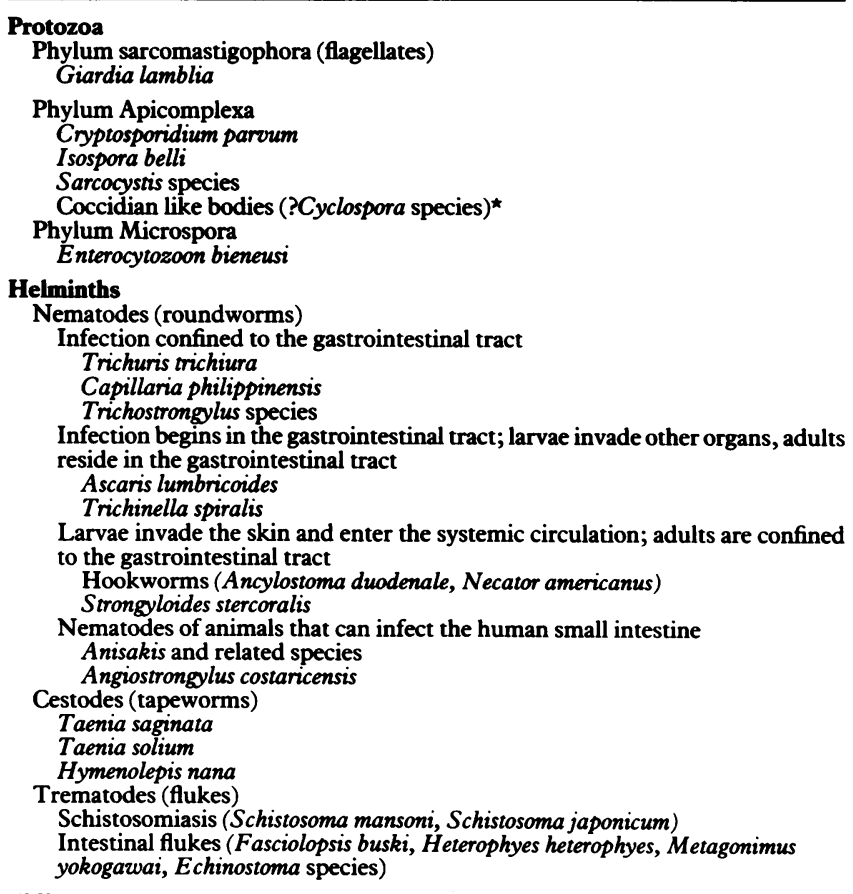

* One group of investigators has recently identified coccidian like (cyanobacterium 
intestine. Novel organisms, a microsporidia species and coccidian like (cyanobacterium like) bodies, which may be a Cyclospora species, have been recognised as human enteric pathogens. Two previously recognised but rarely described protozoa, Cryptosporidium paroum and Isospora belli, have now gained recognition as important causes of diarrhoea worldwide. The emergence of recognition of $C$ parvum, $I$ belli, and microsporidia has been fuelled by the human immunodeficiency virus pandemic as these organisms can cause severe disease in patients with the acquired immunodeficiency syndrome (AIDS). New understanding of disease caused by Giardia lamblia has arisen from recent epidemiological studies, which call into question its role as a pathogen among some indigenous populations in the tropics. Other enteric protozoa, including Entamoeba histolytica, which is one of the most prevalent and dangerous of the enteric parasites, and the less important pathogens Dientamoeba fragilis, Balantidium coli, Entamoeba polecki, and Blastocystis hominis are thought to primarily affect the large intestine and are discussed elsewhere in this series.

Giardia lamblia is prevalent throughout the world. In industrialised countries it is among the most commonly isolated intestinal parasites, occurring primarily in waterborne outbreaks. In developing countries, it is one of the first enteric parasites to infect infants, reaching prevalences of $15-20 \%$ among children under 10 years of age. ${ }^{1-3}$ The pathogenicity of $G$ lamblia varies among epidemiolgical settings. While it is a well reported cause of illness among travellers from areas of low prevalence and during waterborne outbreaks in non-endemic areas, ${ }^{45}$ its role as a pathogen in highly endemic tropical areas has been questioned. Several studies have failed to show an association between infection with $G$ lamblia and symptomatic illness in that setting. ${ }^{67}$ In addition, even after successful treatment, most patients residing in highly endemic areas will be reinfected within a few months. ${ }^{3}$ These findings have led many to advise against routine treatment of asymptomatic patients in tropical settings. ${ }^{7}$ Still, others argue that $G$ lamblia infection may contribute to malnutrition and growth retardation among young children, though the complexity of the interaction between host, parasite, and environment makes this difficult to prove. Studies on this issue have yielded conflicting results. ${ }^{189}$

The diagnosis of giardiasis is usually made by identification of cysts or trophozoites in stool or duodenal specimens. Recently developed commercially available enzyme linked immunosorbent assay (ELISA) and fluorescein labelled monoclonal antibody tests for identifying $G$ lamblia in stool are more sensitive than routine microscopy. ${ }^{1011}$ Treatment for giardiasis includes metronidazole, tinidazole, quinacrine, and furazolidone. ${ }^{12}$

Cryptosporidium species belong to a group of intestinal coccidia that are characterised by a sexual cycle of reproduction that occurs within epithelial cells of the small intestine, ultimately resulting in oocysts, which are excreted in the faeces. Although these organisms have been recognised since the early 1900 s, they were not identified as a human pathogen until 1976. ${ }^{13}$ In recent years there has been emerging recognition of Cryptosporidium paroum as an important cause of diarrhoeal illness worldwide. Although it can affect normal hosts, its most notable impact has been among patients with AIDS, in whom it can cause severe illness.

Cryptosporidiosis has been reported on six continents and is most prevalent in less developed regions. Stool surveys among patients with diarrhoea in North America and the United Kingdom have shown prevalences of $1-4 \% .{ }^{14}$ In contrast, reports of prevalence in Africa, Central and South America, Asia, and Australia range from 3 to $20 \% .{ }^{14}$ In many of these studies Cryptosporidium was considered to be the most significant enteropathogen causing diarrhoeal illness.
Seroprevalence studies show that infection with Cryptosporidium may be even more common than predicted by stool surveys. In the USA and UK, seroprevalence ranges from $25-35 \%{ }^{15-17}$ while in developing countries as many as $64 \%$ of residents have antibodies against Cryptosporidum. ${ }^{18}$ An estimated 250-500 million cases of cryptosporidiosis occur annually among people in Asia, Africa, and Latin America. ${ }^{19}$ Recent studies in the US have found prevalences of $15-16 \%$ among AIDS patients with diarrhoea. ${ }^{2021}$ In developing countries, prevalences of $22-41 \%$ have been reported in that setting. 223

The infection is spread by two main mechanisms, waterborne and person to person. In the tropics infection is more common in warm and rainy months of the year. Cryptosporidium can infect people of all ages but is most common in those under two years. ${ }^{14}$ Breast feeding seems to be protective. ${ }^{24} 25$ Cryptosporidiosis has also been recognised as a cause of travellers' diarrhoea. ${ }^{2627}$

The clinical presentation of cryptosporidiosis is dependent upon the underlying immune state. In immunocompetent persons, the illness begins after an incubation period of about two weeks. ${ }^{14}$ The spectrum of illness ranges from vague epigastric pain, dyspepsia, and mild diarrhoea to severe cholera like diarrhoea (up to 20 litres a day) associated with crampy epigastric pain, weight loss, anorexia, malaise, and flatulence. ${ }^{28-31}$ The illness is self limited, usually resolving in less than two weeks, although it may persist for up to four weeks. In immunocompromised patients, particularly those with AIDS, cryptosporidial infection typically begins with mild diarrhoea and progresses to voluminous watery diarrhoea with severe malabsorption. Unlike immunocompetent patients, patients with AIDS cannot clear the organism, and it often persists for the remainder of the patient's life. A recently identified complication of cryptosporidiosis in patients with AIDS is biliary tract involvement leading to stricture of the distal bile duct similar to sclerosing cholangitis. ${ }^{32} 33$

The diagnosis of cryptosporidiosis is usually based on the identification of oocysts in stool specimens by modified acid fast stain. The oocysts appear as red, oval or crescentic shaped organisms 4-6 microns in diameter. Concentration techniques may aid in the diagnosis when low numbers of organisms are present. A fluorescein labelled monoclonal antibody test that identifies cryptosporidium antigen in stool specimens is commercially available. It is more sensitive than conventional staining. ${ }^{2834}$

The optimal treatment for cryptosporidiosis has yet to be defined. Most ongoing work in this area has been directed towards the treatment of cryptosporidiosis in patients with AIDS. A small number have been successfully treated with hyperimmune bovine colostrum. ${ }^{35-37}$ Although it is hypothesised that IgG and IgA may be the active components, the mechanism of action is unknown. Although many drugs have been tested, recent interest has focused on two oral antibiotics that have shown promise: azithromycin and paromomycin..$^{38-40}$ Both drugs are currently being evaluated in randomised controlled trials. Initial studies suggested that octreatide given subcutaneously, a somatostatin analogue, might be useful in treating cryptosporidium associated diarrhoea in patients with AIDS. A prospective, multicenter trial showed, however, that it had only modest effect. ${ }^{41}$

Isospora belli is another intestinal coccidian, which is known to be an important enteric pathogen in tropical and subtropical climates. It is endemic in South America, Africa, and South East Asia. It can cause disease in immunocompetent hosts and has been recognised as a cause of diarrhoea in travellers. ${ }^{42}$ Its highest prevalence, however, is in immunocompromised patients and it is an important cause of diarrhoea in patients with AIDS. In developing countries, $I$ belli is found in 3-20\% of patients with AIDS. ${ }^{43-46}$ This 
experience is contrasted with the US where the organism is found in $0 \cdot 2 \%$ of AIDS patients. ${ }^{47}$

Clinically, isosporosis presents as a syndrome almost indistinguishable from cryptosporidiosis. It is a self limited diarrhoeal illness in normal hosts, although it may persist for several weeks' duration. In immunocompromised patients with AIDS it can produce severe, chronic diarrhoea associated with malabsorption and weight loss. The diagnosis is made either by identifying oocysts in the stool using a modified acid fast stain or by a small bowel biopsy. After acid fast staining, oocysts are red, ellipsoidal, large (23-33 microns), and contain 1-2 sporoblasts.

Isosporosis responds rapidly to trimethoprim/sulphamethoxazole (TMP/SMX). Metronidazole or pyrimethamine are alternatives in patients with sulphonamide allergy. Unfortunately, relapses are common after treatment in patients with AIDS (up to 50\%). A randomised control trial has shown that recurrences can be prevented with maintenance TMP/SMX given three times weekly or with sulfadoxine/ pyrimethamine once weekly. ${ }^{48}$

Sarcocystis species, closely related to the genus Isospora, have also been implicated as human enteric pathogens. Although usually an infection of skeletal muscle, intestinal infection has been reported. Gastrointestinal symptoms such as nausea, vomiting, and diarrhoea have been described after voluntary ingestion of meat containing Sarcocystis. ${ }^{49}$ In a small series, eosinophilic necrotising enteritis was associated with the presence of Sarcocystis sporocysts in resected specimens of small intestine. ${ }^{50}$

Microsporidia are obligate intracellular protozoa that have a wide host range, which includes invertebrates as well as vertebrates. Recent studies have implicated a newly recognised microsporidia, Enterocytozoon bieneusi as a cause of diarrhoea and malabsorption in patients with AIDS. ${ }^{51-56}$ Prevalence studies using small bowel biopsies have found the organism in $23-50 \%$ of American and European AIDS patients with chronic diarrhoea for which no other cause can be identified. ${ }^{53-56}$ Although seroprevalence surveys are not available from tropical regions, studies of other microsporidia genera suggest that $E$ bieneusi is probably common in tropical areas as well. ${ }^{57}$ One study conducted in Zambia and Uganda showed a prevalence of $6.5 \%$ among AIDS patients with unexplained diarrhoea. ${ }^{58}$

The pathological findings with microsporiodiosis are similar to those in cryptosporidiosis. Infection is confined to small bowel enterocytres resulting in villous atrophy and sloughing of some epithelial cells..$^{55}$ Although characteristic spores can be identified in a modified trichrome or Geimsa stained stool and duodenal aspirates, ${ }^{59-61}$ the diagnosis is usually made by electron microscopy of small bowel biopsy specimens. Effective treatment has not been established, but success with metronidazole or albendazole have been reported in small, uncontrolled series..$^{6263}$

Coccidian like (Cyanobacterium like) bodies (CLB) were first described in the stools of North American travellers returning from Haiti and Mexico with diarrhoea. ${ }^{64}$ Now thought to be an important human enteric pathogen, these organisms have been reported in stools from patients in the USA, Caribbean, Central and South America, South East Asia, and Australasia. CLB have been implicated as the cause of large outbreaks of diarrhoea in Chicago and Nepal. ${ }^{65}$ Recently, investigators studying CLB isolated in Peru proposed that they are coccidians of the genus Cyclospora.$^{66}$ The investigators hypothesised that CLB reported by others may be organisms from that genus. The illness, which occurs in both normal and immunocompromised hosts, is characterised by severe, intermittent watery diarrhoea and fatigue, which can persist for weeks before spontaneous recovery. CLB are described as spherical cysts 8-10 microns in diameter that stain red by modified acid fast stain and are autofluorescent under ultraviolet light. ${ }^{67}$ The exact incidence of disease associated with this organism is not known. There is no known treatment at this time.

\section{Pathogenic nematodes (roundworms) found in the small} intestine

Ascaris lumbricoides, the hookworms Necator americanus and Ancylostoma duodenale, and Trichuris trichiura, which resides predominantly in the colon, are among the most prevalent parasites of humans. In many developing areas of the tropics most residents are heavily infected with more than one of these parasites. In the case of Ascaris and Trichuris infection occurs when ova are ingested in faecally contaminated food and water. In the case of hookworm, infectious filariform larvae invade the skin through bare feet or other exposed skin. A purpuric, papular or vesicular eruption may be seen at the site of entry. After going through a series of developmental stages, which in the case of Ascaris and the hookworms pass through the lung occasionally resulting in pulmonary symptoms, infiltrates and eosinophilia, these nematodes reside as adults in the intestinal tract. They produce a prodigious number of ova, which are disseminated in the environment in stool.

People who are infested with intestinal helminths often complain of abdominal discomfort and may have diarrhoea, but they are also often coincidentally infected with enteropathogenic bacteria or viruses, or both and it is difficult to determine the degree to which the parasites are responsible for their symptoms. When present in large numbers, clumps of Ascaris lumbricoides can produce obstruction of the small intestine, with findings suggestive of an acute abdomen. It is estimated that this occurs in 1 in 1000 subjects in endemic areas. ${ }^{68}$ Individual ascarids, which can grow to more than $30 \mathrm{~cm}$ in length, migrate into the common bile duct or pancreatic duct on occasion producing ascending cholangitis or pancreatitis. ${ }^{69}$ Hookworms, which usually reside in the small intestine, can produce abdominal pain and bloody diarrhoea when subjects are infected for the first time, but are commonly associated with iron deficiency anaemia, which may be severe when the worm burden is high and iron intake is limited..$^{71}$ Trichuris trichiura is associated with blood loss from the colon, chronic diarrhoea, and occasionally rectal prolapse. ${ }^{72}{ }^{73}$ Mass treatment programmes in areas where all three of these parasites are endemic, suggest that they produce malnutrition and adversely affect growth in children who are heavily infected..$^{74}$

The diagnosis of Ascaris, hookworm, or Trichuris infection is typically made by finding ova in the stool. These parasites are susceptible to a number of anthelmintic agents. Mebendazole and albendazole are active against all three. ${ }^{12}$ Albendazole, which has not yet been licensed in the United States, has the advantage of being effective when given as a single dose and has been successfully used in mass treatment programmes. ${ }^{74}$

Strongyloides stercoralis, another small bowel pathogen, is also endemic in many tropical areas. Similar to hookworm, larvae invade through the skin and may elicit pulmonary infiltrates with eosinophilia as they migrate through the lungs or a pruritic skin lesion known as larva currens. ${ }^{75}$ Strongyloides adults in the intestine can produce abdominal discomfort, diarrhoea, and eosinophilia ${ }^{75}$ Strongyloides differ from the intestinal nematodes previously discussed in that autoinfection can occur. Disseminated hyperinfection may occur in subjects with compromised $\mathrm{T}$ cell immunity associated with steroid use, neoplasm, malnutrition, or infrequently AIDS..$^{76-80}$ The diagnosis is made by identifying rhabditiform or filariform larvae in the stool. ${ }^{81}$ Thiabendazole is effective in treating strongyloidiasis, but is commonly associated with nausea, vomiting, and other side 
effects. ${ }^{82}$ Ivermectin, which is much better tolerated, is promising in preliminary studies. ${ }^{83}$

Trichinella species, another nematode capable of causing pathology in the small intestine, are prevalent worldwide, including the tropics. The intestinal phase of trichinosis occurs in the first week after ingestion of meat infected with Trichinella cysts when larvae penetrate the small bowel epithelium and develop into the adult stage. This phase is associated with nausea, abdominal pain, and diarrhoea and is quickly followed by periorbital oedema and muscle pain as newborn larvae penetrate into muscle cells. A less common syndrome of chronic diarrhoea has been described in Inuit Indians in North America infected with $T$ nativa. This unusual presentation is felt to be the result of secondary infection in previously infected subjects. ${ }^{84}$

A number of other pathogenic intestinal roundworms that inhabit the small bowel are found in the tropics. Trichostrongylus species are important pathogens of cattle, and are found in humans in cattle raising areas. Human infection is usually mild or asymptomatic. ${ }^{85}$ Capillaria philippinesis, which is endemic in scattered areas of South East Asia and the Philippines, can result in malabsorption, chronic diarrhoea, wasting, and death. Humans typically become infected when they ingest contaminated fish. ${ }^{86}$ Angiostrongylus costaricensis occurs in scattered areas of Latin America. Humans become infested when they ingest food contaminated by infected land snails. The parasite causes acute inflammatory lesions of the small intestine or colon and may be confused with bacterial infections, acute appendicitis, Meckel's diverticulum or neoplasm. Many cases come to surgical exploration and resection. ${ }^{87}$ Anisakiasis occurs when inadequately cooked fish contaminated with anisakine larvae is ingested. Acute inflammatory lesions may be found in the stomach or small intestine at the sites where larvae attempt to invade. ${ }^{88} 89$

Pathogenic trematodes (flukes) found in the small intestine A number of flukes, or trematodes, are pathogens of humans. They have complex life cycles involving snails. They gain access to their human hosts either by entering the skin, as is the case for Schistosoma species, or when they are consumed in uncooked, contaminated food. Schistosomiasis is the most prevalent and important of the helminthic infections. Schistosoma mansoni is endemic throughout Africa and is found in many areas of Latin America and the Middle East. Schistosoma japonicum is found in Asia. Adult schistosomes reside in venules in the mesenteric plexus where they release their ova. Intestinal disease is characterised by mucosal inflammation, hypertrophy, and ulceration. Those infected may complain of abdominal pain, diarrhoea, and bloody stools. Intestinal polyps and strictures may result late in disease. ${ }^{0}$ Eggs that are swept back to the liver elicit granulomatous inflammatory responses. Fibrosis of varying severity results and can lead to presinusoidal portal hypertension and hepatosplenomegaly. ${ }^{91}$

The diagnosis is usually made by finding the ova in stool or biopsy specimens, but it may be suggested by the identification of anti-schistosomal antibodies. Diffuse or patchy mucosal hyperaemia and friability may be seen at colonscopy. ${ }^{92}$ Praziquantel has been effective in the treatment of all forms of schistosomiasis. Oxamniquine can be used to treat Schistosoma mansoni. ${ }^{12}$

Several flukes live within the gastrointestinal tract. Fasciolopsis buski, which is acquired when people ingest contaminated raw water plants such as the water chestnut, results in inflammation of the small intestine and epigastric pain, nausea, and diarrhoea of varying severity. Similar symptoms may be seen with two other intestinal flukes, Heterophyes heterophyes and Metagonimus yokogawai, which are acquired when contaminated fresh water fish are con- sumed, ${ }^{93}{ }^{94}$ or Echinostoma species, which are ingested in raw, infected snails, amphibians or fish. ${ }^{95}$

\section{Pathogenic tapeworms (cestodes) found in the small intestine}

Tapeworms have complex life cycles. Adults live in the intestinal tract of their definitive host while larvae are found encysted in the tissue of intermediate hosts such as cattle or pigs. Despite reaching extraordinary lengths in humans, adult Taenia saginata and Taenia solium tapeworms cause minimal disease. When ova of Taenia solium, the pork tapeworm, are ingested by humans, however, they can produce cysts in the brain and other tissues, a condition known as cysticercosis. ${ }^{96}$ Neurocyticercosis is an important cause of morbidity and death in Latin America and in some areas of Asia and Africa. In the case of the dwarf tapeworm, Hymenolepis nana, humans serve as both the intermediate and definitive host and autoinfection is prominent. Infection is thought to occur in 20 million people worldwide. Light infections are typically asymptomatic, but heavy infections can produce loss of appetite, abdominal discomfort, diarrhoea, and anorexia. ${ }^{97}$ Niclosmide and praziquantel are active against adult tapeworms in the intestinal tract; praziquantel or albendazole can be used in the treatment of neurocyticercosis. ${ }^{989}$

J JERNIGAN R L GUERRANT
R D PEARSON

Departments of Internal Medicine and Pathology,

Division of Geographic and International Medicine,

University of Virginia School of Medicine,

Charlottesville, Virginia, USA

1 Farthing MJG, Mata L, Urrutia JJ, Kronmal RA. Natural history of Giardia infection of infants and children in rural Guatemala and its impact on physical growth. Am f Clin Nutr 1986; 43: 395-405.

2 Gilman RH, Brown KH, Visvesvara GS, et al. Epidemiology and serology of Giardia lamblia in a developing country: Bangladesh. Trans $R$ Soc Trop Med Hyg 1985; 79: 469-73.

3 Gilman RH, Marquis GS, Miranda E, Vestegui M, Martinez H. Rapid reinfection by Giardia lamblia after treatment in a hyperendemic third world community. Lancet 1988 ; i: 343-5. Union. F Infect Dis 1974; 130: 319-23.

(1965-84. Lancet 1986; ii: 513-4.

6 Stevens DP. Selective primary health care: strategies for control of disease in the developing world. XIX. Giardiasis. Rev Infect Dis 1985; 7: 530-5.

7 Sullivan PS, DuPont HL, Arafat RR, et al. Illness and reservoirs associated with Giardia lamblia infection in rural Egypt: the case against treatment in developing world lamblia infection in rural Egypt: the case against treatment in

8 Sullivan PB, Lunn PG, Northrop-Clewes CA, Farthing MJ. Parasitic infection of the gut and Sullivan PB, Lunn PG, Northrop-Clewes CA, Farthing MJ. Parasitic infect.
protein-losing enteropathy. F Pediatr Gastroenterol Nutr 1992; 15: 404-7.

protein-losing enteropathy $\mathrm{SH}$. Shapiro SH, et al. Asymptomatic giardiasis in children
Ish-Horowicz M, Korman Pediatr Infect Dis $\mathcal{F} 1989 ; 8: 773-9$.

10 Addiss DG, Mathews HM, Stewart JM, et al. Evaluation of a commercially available enzyme-

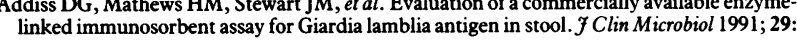
linked im $1137-42$.

11 Stazzone A, Kleinosky M, Mourad A, Watson RR, Murphy JR. Frequency of Giardia and Cryptosporidium infections as detected by conventional and Merifluor $\mathrm{r}^{\mathrm{TM}}$ methods. Abstracts of the 93rd General Meeting of the American Society of Microbiology 1993. Abstracts of the 93rd General Meeting of the American Society

[Abstract]. Washington, DC, Am

13 Nime FA, Burek JD, Page DL, Holscher MA, Yardley JH. Acute enterocolitis in a huma Nime FA, Burek JD, Page DL, Holscher MA, Yardley JH. Acute enterocolitis in a human being infected with the protozoan Cryptosporidium. Gastroenterology 1976; 70: $592-8$. 458-83.

15 Casemore DP. The antibody response to Cryptosporidium: development of a serological test and its use in a study of immunologically normal persons. F Infect 1987; 14: 125-34.

16 Hayes EB, Matte TD, O'Brien TR, et al. Large community outbreak of cryptosporidiosis due to contamination of a filtered public water supply. $N$ Engl f Med 1989; 320: 1372-6.

17 Koch KL, Phillips DJ, Aber RC, Current WL. Cryptosporidiosis in hospital personnel: evidence for person-to-person transmission. Ann Intern Med 1985; 102: 593-6.

evidence for person-to-person transmission. Ann Intern Med 1985; 102: 593-6.
Ungar BL, Gilman RH, Lanata CF, Perez-Schael I. Seroepidemiology of Cryptosporidium ungar BL, Gilman RH, Lanata CF, Perez-Schael I. Seroepidemiology of Cry.
infection in two Latin American populations. I Infect Dis 1988; 157: 551-6.

infection in two Latin American populations. F Infect Dis 1988; 157: 551-6.
9 Current WL, Garcia LS. Cryptosporidiosis. Clin Microbiol Rev 1991; 4: 325-58.

20 Laughon BE, Druckman DA, Vernon A, et al. Prevalence of enteric pathogens in homosexual men with and without acquired immunodeficiency syndrome. Gastroenterolog 1988; 94: 984-93.

21 Smith PD, Lane HC, Gill VJ, et al. Intestinal infections in patients with the acquired immunodeficiency syndrome (AIDS): Etiology and response to therapy. Ann Intern Med 1988; 108: 328-33.

22 Malebranche R, Arnoux E, Guerin JM, et al. Acquired immunodeficiency syndrome with severe gastrointestinal manifestations in Haiti. Lancet 1983; ii: 873-8.

23 Henry MC, De Clercq D, Lokombe B, et al. Parasitological observations of chronic diarrhoea in suspected AIDS adult patients in Kinshasa (Zaire). Trans $R$ Soc Trop Med Hyg 1986; 80: 309-10.

24 Mata L, Bolanos $\mathbf{H}$, Pizarro D, Vives $M$. Cryptosporidiosis in children from some highland Costa Rican rural and urban areas. Am $\mathcal{F}$ Trop Med Hyg 1984; 33: 24-9.

25 Mata L. Cryptosporidium and other protozoa in diarrheal disease in less developed countries. Pediatric Infectious Disease 1986; 5 (suppl 1): S117-S30

26 Soave R, Ma P. Cryptosporidiosis: traveler's diarrhea in two families. Arch Intern Med 1985, 145: 70-2.

27 Gatti S, Cevini C, Bruno A, Bernuzzi M, Scaglia M. Cryptosporidiosis in tourists returning from Egypt and the Island of Mauritius. Clin Infect Dis 1993; 16: 344-5. 
28 Flanigan TP, Soave R. Cryptosporidiosis. Prog Clin Parasitol 1993; 3: 1-20.

29 Kotler DP, Francisco A, Clayton F, Scholes JV, Orenstein JM. Small intestinal injury and parasitic diseases in AIDS. Ann Intern Med 1990; 113: 444-9.

30 Gillin JS, Shike M, Alcock N, et al. Malabsorption and mucosal abnormalities of the small intestine in the acquired immunodeficiency syndrome. Ann Intern Med 1985; 102: 619-22.

31 Kotler DP, Gaetz HP, Lange M, Klein EB, Holt PR. Enteropathy associated with the acquired immunodeficiency syndrome. Ann Intern Med 1984; 101: 421-8.

32 Blumberg RS, Kelsey P, Perrone T, Dickerson R, Laquaglia $M$. Cytomegalovirus - and Cryptosporidium-associated acalculous gangrenous cholecystitis. Am $\mathcal{J}$ Med 1984; 76: 1118-23.

33 Margulis SJ, Honig CL, Soave R, Govoni AF, Mouradian JA, Jacobsen IM. Biliary tract obstruction in the acquired immunodeficiency syndrome. Ann Intern Med 1986; 105: 207-10.

34 Weber R, Bryan RT, Bishop HS, Wahlquist SP, Sullivan JJ, Juranek DD. Threshold of detecting Cryptosporidium oocysts in human stool specimens: evidence for low sensitivity of current diagnostic methods. F Clin Microbiol 1991; 29: 1323-7.

35 Ungar BL, Ward DJ, Fayer R, Quinn CA. Cessation of Cryptosporidium-associated diarrhea in an acquired immunodeficiency syndrome patient after treatment with hyperimmune bovine colostrum. Gastroenterology 1990; 98: 486-9.

36 Tzipori S, Roberton D, Chapman C. Remission of diarrhoea due to cryptosporidiosis in an immunodeficient child treated with hyperimmune bovine colostrum. BMF 1986; 293: 1276-7.

37 Tzipori S, Robertson D, Cooper DA, White L. Chronic cryptosporidial diarrhoea and hyperimmune cow colostrum. Lancet 1987; ii: 344-5.

38 Petersen C. Cryptosporidiosis in patients infected with the human immunodeficiency virus. Clin Infect Dis 1992; 15: 903-9.

39 Armitage K, Flanigan T, Carey J, et al. Treatment of cryptosporiosis with paromomycin. A report of five cases. Arch Intern Med 1992; 152: 2497-9.

40 Fichtenbaum CJ, Ritchie DJ, Powderly WG. Use of paromomycin for treatment of cryptosporidiosis in patients with AIDS. Clin Infect Dis 1993; 16: 298-300.

41 Cello JP, Grendell JH, Basul P, et al. Effect of octreotide on refractory AIDS-associated diarrhea - a prospective, multicenter clinical trial. Ann Intern Med 1991; 115: 705-10.
42 Shaffer N, Moore L. Chronic travelers' diarrhea in a normal host due to Isospora belli. J Infect Dis 1989; 159: 596-7.

43 Pape JW, Johnson WD Jr. Isospora belli infections. Prog Clin Parasitol 1991; 2: 119-27. 44 DeHovitz JA, Pape JW, Boncy M, Johnson WD Jr. Clinical manifestations and therapy of Isospora belli infection in patients with the acquired immunodeficiency syndrome. N Engl f Med 1986; 315: 87-90.

45 Sewankambo N, Mugerwa RD, Goodgame R, et al. Enteropathic AIDS in Uganda. An endoscopic, histological and microbiological study. AIDS 1987; 1: 9-13.

46 Pape JW. Treatment of gastrointestinal infections. AIDS 1988; 2 (suppl 1): S161-7.

47 Soave R. Johnson WD Jr. Cryptosporidium and Isospora belli infections. $\mathcal{F}$ Infect Dis 1988; 157: 225-9.

48 Pape JW, Verdier RI, Johnson WD Jr. Treatment and prophylaxis of Isospora belli infection in patients with the acquired immunodeficiency syndrome. $N$ Engl f Med 1989; 320: in patien.

49 Hunter's tropical medicine. Philadelphia: WB Saunders, 1991 .
50 Bunyaratvej S, Bunyawongwiroj P, Nitiyanant P. Human intestinal sarcosporidiosis: report of six cases. Am $\mathcal{J}$ Trop Med Hyg 1982; 31: 36-41.

51 Desportes I, Le Charpentier Y, Galian A, et al. Occurrence of a new microsporidian: enterocytozoon bieneusi $\mathrm{ng}, \mathrm{n} \mathrm{sp}$, in the enterocytes of a human patient with AIDS. f Protozool 1985; 32: $250-4$.

52 Modigliani R, Bories C, Le Charpentier Y, et al. Diarrhoea and malabsorption in acquired immune deficiency syndrome: a study of four cases with special emphasis on opportunistic protozoan infestations. Gut 1985; 26: 179-87.

53 Greenson JK, Belitsos PC, Yardley JH, Bartlett JG. AIDS enteropathy: occult enteric infections and duodenal mucosal alterations in chronic diarrhea. Ann Intern Med 1991; 114: 366-72.

54 Molina JM, Sarfati C, Beauvais B, et al. Intestinal microsporidiosis in human immunodeficiency virus-infected patients with chronic unexplained diarrhea: prevalence and deficiency virus-infected patients with chronic unexplained

55 Orenstein JM, Chiang J, Steinberg W, Smith PD, Rotterdam H, Kotler DP. Intestinal microsporidiosis as a cause of diarrhea in human immunodeficiency virus-infected patients: a report of 20 cases. Hum Pathol 1990; 21: 475-81.

56 Eeftinck Schattenkerk JK, van Gool T, Van Ketel RJ, et al. Clinical significance of smallintestinal microsporidiosis in HIV-1-infected individuals. Lancet 1991; 337: 895-8.

57 Bryan RT, Cali A, Owen RL, Spencer HC. Microsporidia: opportunistic pathogens in patients with AIDS. In: Sun T, ed. Progress in clinical parasitology, vol 2. Philadelphia: Field and Wood, 1990; 1 .

58 Lucas SB, Papadaki L, Conlon C, Sewankambo N, Goodgame R, Serwadda D. Diagnosis of intestinal microsporidiosis in patients with AIDS. F Clin Pathol 1989; 42: 885-7. 59 van Gool T, Hollister WS, Schattenkerk JE, et al. Diagnosis of Enterocytozoon bieneusi
microsporidiosis in AIDS patients by recovery of spores from faeces. Lancet 1990; 336: 697-8.

60 Rijpstra AC, Canning EU, Van Ketel RJ, Eeftinck Schattenkerk JK, Laarman JJ. Use of light microscopy to diagnose small-intestinal microsporidiosis in patients with AIDS.

61 Weber R, Bryan RT, Owen RL, Wilcox CM, Gorelkin L, Visvesvara GS. Improved light- microscopical detection of microsporidia spores in stool and duodenal aspirates. $N \mathrm{Engl} \mathcal{F}$ Med 1992; 326: 161-6.

62 Blanshard C, Ellis DS, Tovey DG, Dowell S, Gazzard BG. Treatment of intestinal microsporidiosis with albendazole in patients with AIDS. AIDS 1992; 6: 311-3.

63 Canning EU, Hollister WS. Enterocytozoon bieneusi (Microspora): prevalence and pathogenicity in AIDS patients. Trans $R$ Soc Trop Med Hyg 1990; 84: 181-6.

64 Soave R, Dubey JP, Ramos LJ, Tummings M. A new intestinal pathogen? Clin Res 1986; 34: 533A.

65 Outbreaks of diarrheal illness associated with Cyanobacteria (Blue-green algae)-like bodies Chicago and Nepal, 1989 and 1990. MMWR 1991; 40: 325-7.

66 Ortega YR, Sterling CR, Gilman RH, Cama VA, Diaz F. Cyclospora species - a new protozoan pathogen of humans. N Englf Med 1993; 328: 1308-12.

67 Long EG, White EH, Carmichael Ww, et al. Morphologic and staining characteristics of a cyanobacterium-like organism associated with diarrhea. I Infect Dis 1991; 164: 199-202. 68 Blumenthal DS, Schultz MG. Incidence of intestinal obstruction in children infected with Ascaris lumbricoides. Am $\mathcal{F}$ Trop Med Hyg 1975; 24: 801-5.

69 Khuroo MS, Zaregar SA, Mahajan R. Hepatobiliary and pancreatic ascariasis in India. Lancet 1990; 335: 1503-6.

70 Maxwell C, Hussain R, Nutman TB, et al. The clinical and immunologic responses of normal human volunteers to a low dose hookworm (Necator americanus) infection. Am $\mathcal{F}$ Trop Med Hyg 1987; 37: 126-34.

71 Gilman RH. Hookworm disease: host-pathogen biology. Rev Infect Dis 1982; 4: 824-9.

72 MacDonald TT, Choy MY, Spencer J, et al. Histopathology and immunochemistry of the caecum in children with Trichuris dystentery syndrome. F Clin Pathol 1991; 44: 194-9. Gilman RH, Chong TH, David C, Greenberg B, Virik HK, Dixon HB. The adverse
consequences of heavy Trichuris infection. Trans $R$ Soc Trop Med Hyg 1983; 77: 432-8.

consequences of heavy Trichuris infection. Trans R Soc Trop Med Hyg 1983; 77: 432-8.
74 Stephenson LS, Latham MC, Kurz KM, Kinoti SM, Brigham H. Treatment with a single dose of albendazole improves growth of Kenyan schoolchildren with hookworm, Trichuris dose of albendazole improves gromes infections. Am f Trop Med Hyg 1989; 41: 78-87.

75 Nutman TB, Ottesen EA, Ieng S, et al. Eosinophilia in Southeast Asian refugees: evaluation at a referral center. F Infect Dis 1987; 155: 309-13.

76 Morgan JS, Schaffner W, Stone WJ. Opportunistic strongyloidiasis in renal transplant

77 Berk SL Vients. Transplantation 1986; 42: S18-24.

of strongyloidiasis: A prospective study in rural Tennessee. Arch Intern Med 1987; 147:
ond $1257-61$

78 Paola D, Dias LB, Silva JR. Enteritis due to Strongyloides stercoralis: a report of 5 fatal cases. Am f Dig Dis 1962; 7: 1086

79 Bartholomew C, Butler AK, Bhaskar AG, Jankey N. Pseudo-obstruction and a sprue-like syndrome from strongyloidiasis. Postgrad Med f 1977; 53: 139-42.

80 Petithory JC, Derouin F. AIDS and strongyloidiasis in Africa. Lancet 1987; i: 921.

81 Lima JP, Delgado PG. Diagnosis of strongyloidiasis: importance of Baermann's method. Am $\mathcal{F}$ Dig Dis 1961; 6: 899.

82 Grove DI. Treatment of strongyloidiasis with thiabendazole: an analysis of toxicity and effectiveness. Trans $R$ Soc Trop Med Hyg 1982; 76: 114-8.

83 Gann PH, Neva FA, Gam AA. A randomized trial of single and two-dose ivermectin vs. thiabendazole for chronic, uncomplicated strongyloidiasis [Abstract]. Am f Trop Med Hyg

84 MacLean JD, Poirier L, Gyorkos TW, et al. Epidemiologic and serologic definition of primary and secondary trichinosis in the Arctic. F Infect Dis 1992; 165: 908-12.

85 Wolfe MS. Oxyuris, trichostrongylus and trichuris. Clin Gastroenterol 1978; 7: 201-17.

86 Cross JH. Intestinal capillariasis. Clin Micro Rev 1992; 5: 120.

87 Hulbert TV, Larsen RA, Chandrasoma PT. Abdominal angiostrongyliasis mimicking acute appendicitis and Meckel's diverticulum: report of a case in the United States and review. Clin Infect Disc 1992;14: 836-40.

88 Kwee HG, Sautter RL. Anisakiasis. Am Fam Physician 1987; 36: 137-40.

89 Smith JW, Wootten R. Anisakis and anisakiasis. Adv Parasitol 1978; 16: 93-163.

Kamel IA, Elwi AM, Cheever AW, Mosimann JE, Danner R. Shistosoma mansoni and 931-8.

91 Cheever AW, Kamel IA, Elwi AM, Mosimann JE, Danner R, Sippel JE. Shistosoma mansoni and S. haematobium infections in Egypt. III. Extrahepatic pathology. Am $\mathcal{f}$ Trop Med Hyg 1978; 27: 55-75.

92 Radhakrishnan S, Al Nakib B, Shaikh H, Menon NK. The value of colonoscopy on schistosomal, tuberculous and amebic colitis. Dis Colon Rectum 1986; 29: 891-5.

93 Adams KO, Jungkind DL, Bergquist EJ, Wirts CW. Intestinal fluke infection as a result of eating sushi. Am f Clin Pathol 1986; 86: 688-9.

94 Goldsmith RS. Chronic diarrhea in returning travelers: Intestinal parasite infection with the fluke Metagonimus yokogawi. South Med $\mathscr{f}$ 1978; 71: 1513-5.

95 Huffman JE, Fried B. Echinostoma and echinostomiasis. Adv Parasitol 1990; 29: 215-69. 96 Despommier DD. Tapeworm infection - the long and the short of it. $N$ Engl f Med 1992; 327: 727.

97 Biagi F, Lopez R, Viso J. Analysis of symptoms and signs related with intestinal parasitosis in 5,215 cases. Prog Drug Res 1975; 19: 10-22.

98 Pearson RD, Wilson ME. Role of praziquantel in the treatment of helminthic diseases. Internal Medicine for the Specialist 1986; 7 : 183. 99 King CH, Mahmoud AAF. Drugs for five years later: praziquantel. Ann Intern Med 1989;
110: 290-6. 